\title{
Children with Vesicoureteric Reflux in a Tertiary Level Teaching Hospital I Nzan ${ }^{1}$, RM Ali ${ }^{2}$ MI Ilias ${ }^{1}, \mathrm{~A} \mathrm{Nasir}^{1}, \mathrm{AH} \mathrm{Khan}^{3}$, RA Aftab ${ }^{1}$
}

\begin{abstract}
Objective: To determine the survival analysis of children with Vesicoureteric reflux (VUR) in relation to the development of renal failure, and the associated factor in relation with high grade VUR.

Method: A retrospective study of all children diagnosed with VUR whom were treated from the paediatrics wards and clinics was undertaken. Children whose medical records were not able to be traced and patients who have underlying chronic diseases such as SLE, Nephrotic Syndrome and children on chemotherapy medications were excluded from the study. Informed consent was obtained from the subjects after being given a full explanation of the study procedure.

Results: Forty-five children had VUR. The mean age of presentation was $1.3(\mathrm{SD} \pm 0.66)$ years old. A majority of them were boys $30(66.7 \%)$. Twenty-two children (48.9\%) had bilateral VUR. Thirty-one children $(68.9 \%)$ had high grade VUR. VUR were complicated with recurrence UTI $(24,53.3 \%)$ and renal failure $(14,31.1 \%)$. The median survival time for the children in the high grade VUR group to develop renal failure was eight years. Presence of bilateral VUR was found to be significantly associated with renal failure after adjusting for gender, presence of UTI, income and education [OR $(95 \% \mathrm{CI}): p$ value: $5.7(1.22,26.33): p=0.027]$. There was a significant association between children with high grade VUR and the degree of renal failure, where the $p$ value was 0.034 .
\end{abstract}

Conclusion: A majority of patients with vesicoureteric reflux were of high grade reflux and could potentially lead to renal failure. Predictive factor for renal failure was bilateral VUR.

Keywords: Children, renal failure, survival time, vesicoureteric reflux

From: ${ }^{1}$ Department of Paediatrics, School of Medical Sciences, Universiti Sains, Kubang Kerian 16150, Kelantan, ${ }^{2}$ Department of Paediatrics, Universiti Sultan Zainal Abidin (UniSZA), Gong Badak Campus, 21300 Kuala Terengganu, Terengganu, ${ }^{3}$ Department of Clinical Pharmacy, School of Pharmaceutical Sciences, Universiti Sains Malaysia, 11800 Penang Malaysia.

Correspondence: Dr A Khan, Department of Clinical Pharmacy, School of Pharmaceutical Sciences, Universiti Sains Malaysia, 11800 Penang Malaysia.Email: dramer2006@ gmail.com 


\section{INTRODUCTION}

Vesicoureteric reflux (VUR) is a common finding in pediatric practice. It occurs in about $1.0 \%$ of children, with several genetic loci involved. Vesicoureteric reflux has been identified as a risk factor for the development of urinary tract infections (UTI) and is present in a third of young children with VUR. About 20.0 to $30.0 \%$ will have further infections, but few will experience long-term renal sequelae (1). Vesicoureteric reflux (VUR) is characterized by the retrograde flow of urine from the bladder to the kidneys. It occurs in approximately $1.0-3.0 \%$ of children and is associated with $7.0-17.0 \%$ of children diagnosed with end-stage renal disease worldwide (2). The prevalence in boys (78.0\%), the severity (grade IV-V), and the early age at diagnosis (18.0\% prenatally) suggested that congenital renal damage was the major cause of paediatric chronic renal failure (3).

Higher grades of reflux had been associated with decreased resolution rates and increased prevalence of renal scars (2). In general, the severity or grade of VUR has been used as the main factor to determine the likelihood of spontaneous reflux resolution and risk of renal injury. Other factors have been shown to be predictive of reflux resolution and/or the risk of renal injury that include age, sex, laterality, bladder volume and pressure at the onset of reflux, presence of renal scars, presence of voiding dysfunction and history of urinary tract infection (4).

Management of children with VUR remains controversial because there is no strong supportive evidence that prophylactic antibiotics or surgical intervention improve outcomes. The resolution of VUR is more likelihood to occur when the grade of VUR was at the lowest and unilateral (5). There was no local Malaysian data regarding prevalence, profile and outcome of children with VUR reported. 
The severity of reflux is expressed as a grade, which is based on the system established by the International Reflux Study in Children (6). Our study is hoped to establish local data, describing their demographic profile, survival of children with VUR developing Chronic Kidney Disease (CKD) stage $3-5$ and looking for associated risk factors for in the development of renal failure.

\section{METHODOLGY}

A retrospective cohort study on children with VUR that fulfilled the inclusion criteria was included. Clinical data of all children who attended the Paediatric Clinic or were admitted to the Paediatric Surgical Ward and Paediatric Ward in HUSM with the diagnosis of VUR from January 1999 to December 2010 were reviewed and analysed. The cases were identified by searching for the diagnosis of VUR from the records office's computer databases. We also included children with diagnosis with urinary tract infection (UTI) and spina bifida with neurogenic bladder to prevent missing cases of VUR as these diagnoses have a known association.

The initial total cases collected were 75 children but due to missing data and investigation records, only 45 children were finally included in our study. Contact by phone calls was made in some of the cases who had defaulted follow-up to determine their current status.

Data regarding demographic profile, associated factors for renal failure and documented complications, as well as drugs used as prophylaxis in these children with VUR were collected. Outcome measure of frequency of relapses of UTI and the growth of organisms were analysed. Voiding cystourethrogram (VCUG) and dimercaptosuccinic acid (DMSA) scans that were done in most of these patient were reviewed, analysed and grading of VUR 
and documentation of scarring were based on the findings from these investigations. A written Consent was taken from patient's parents to participate in current study

\section{Ethical approval}

The study had been presented and approved by the Universiti Sains Malaysia Research Ethics Committee (Human) (ref number usm/kk/ppp/JEPeM(212.4(2.4)).

\section{Statistical analysis}

The main investigator manually checked and entered all the data after reading through all the data collected and subsequently all the data were entered into the computer. All the result was analysed using Predictive Analytics SoftWare (PASW) Statistics 18.0. Demographic data (age, sex, race, and district), complication of the CKD were presented by percentage, mean and standard deviation.

Survival analysis was done using Kaplan Meier Survival Analysis. The analysis was used to see the time of development of renal failure in children with VUR. Simple logistic regression was used to see the possible factors associated with high grade VUR and possible factors associated with renal failure.

\section{RESULTS}

The mean age of presentation was $1.3(\mathrm{SD} \pm 0.66)$ year old. A majority of patients were boys $(\mathrm{n}=30,66 \%)$. Malay was the main ethnic group comprising 40 (88.9\%), followed by Chinese $4(8.9 \%)$ and Indian $1(2.2 \%)$. Twenty three (51\%) children were from Kota Bharu that represented the major part of our subject, followed by Bachok (11.1\%), Machang (4\%), Pasir Mas (4.4\%), Kuala Krai (2.2\%), and Tumpat (2.2\%) district (table 1) 
Twenty one children (46.4\%) came from a family with income of less than RM 1000. Two (4.4\%) children were from a family with income of RM 400 - RM 699, 19 children (31.1\%) from family with an income of RM 700 - RM 999. Twenty-four (53.3\%) of them had an income of more than RM 1000 (table 2)

Twenty children (44.4\%) had primary VUR and 25 children (55.5\%) had secondary VUR. A majority (28.9\%) of the secondary causes of VUR were neurogenic bladder associated with spina bifida, followed by posterior urethral valve (13.3\%), PUJ obstruction (2.2\%), anorectal malformation (2.2\%), tethered cord (2.2\%) and bilateral duplex kidney (2.2\%) [Table 2].

Twenty-three $(51.1 \%)$ children with VUR affected single ureter and twenty-two (48.9\%) had bilateral ureters involved. Thirty-three (47.8\%) were at the right ureter and thirtysix $(52.1 \%)$ were on the left. Most of the patients (40\%) were with VUR grade IV, followed by VUR grade V $(13,28.8 \%)$, VUR grade III $(4,8.8 \%)$ whereas grades I and II had same five (11.1\%) patients each (table 3 ).

There were 14 children with low grade VUR and 13 cases were censored cases. The cases were censored because they did not develop renal failure during the end of the study period. Only one of them developed renal failure. However for children with high grade VUR, there were 31 children and 13 of them had renal failure. Eighteen of them were censored cases. The median survival time for the children in the high grade VUR group to develop renal failure (CKD stage 3 - 5) was 8 years (96 months) (figure 1). The median survival time for children with low grade VUR group could not be measured because only one case was presented with renal failure. The association of high grade VUR to develop renal failure (CKD stage 3 - 5) was found to be significant, $p=0.034$.

In determining the predictive factors for the development of renal failure (CKD stage 3 - 5) in children with VUR, laterality had a significant association ( $\mathrm{p}=0.017)$. No other patient 
factor had any statistically significant association with the development of renal failure (table 4).

\section{DISCUSSION}

In the current study, there were 30 boys $(66.7 \%)$ and 15 girls $(33.3 \%)$, giving the boy to girl ratio of 2:1. The result was similar to a study done by Yip and colleagues (2007) where male: female children with VUR were 2:1 also (4). However, a study done in Brazil observed the incidence of vesicoureteric reflux to be four times higher in females compared to male $(81.6 \%$ against $18.4 \%$ ) (7). Caione et al. reported that male gender is confirmed as having a high risk for renal parenchymal damage in grossly bilateral VUR detected within the first year of life (8).

Analysis from the current study indicates that there was a significant association between high grade VUR and the degree of renal failure. Logically children who have a high grade VUR will have a severe spectrum of renal failure. The study also shows that bilateral VUR was associated with the development of renal failure. Silva and collegues also had similar data but they also found that with the development of renal failure serum creatinine of $>6 \mathrm{mg} / \mathrm{L}$ in the first year, age of diagnosis more of than 24 months old and a delay in diagnosis of VUR were significantly associated (9). However Silva and collegues recruited a large sample of 184 children over 24 year's duration. Obviously, the result would be more significant compared to our study since our sample size was only 45 children over 12 year's duration. Apart from that, age of less than one year at presentation and recurrent UTI were predictive factors for high grade VUR. Zaffanello and collegues reported that children being presented in the first two years of age with complicated UTI and with severe degree of VUR were the possible causes of Chronic Kidney Disease (10).

The mean time for children with high grade VUR to develop renal failure was eight years. Silva et al evaluated the probability of CKD at 10 years after VUR was diagnosed (9). 
They found out that in VUR grade III, $0 \%$ of children had a probability to get CKD, $22.0 \%$ of children in grade IV and $26.0 \%$ for grade V. They also looked from another perspective where probability of CKD was $35.0 \%$ for bilateral renal damage and $11.0 \%$ for unilateral renal damage.

A majority of the VUR occurrence in our children was due to secondary VUR. However, other studies revealed that most of their cases were primary VUR and they were familiar with the involvement of several genetic loci $(4,11)$. Primary VUR was usually diagnosed after finding prenatal hydronephrosis. It is usually associated with a congenital renal disease (12). In our study five children (11.1\%) were presented with congenital hydronephrosis and were found to have primary VUR. Secondary VUR were due to neurogenic bladder in children with spina bifida, sacral agenesis, posterior urethral valves, pelviuretheric junction obstruction, anorectal malformation and congenital abnormality of genitourinary system.

A study by Matsumoto et al. revealed neurogenic bladder causes $38.0 \%$ of vesicoureteric reflux with UTI (13). Secondary VUR is the leading cause for renal failure as compared to primary VUR where only 3 children had renal failure in primary VUR. However, Lama et al reported that in primary VUR, diagnosis of VUR during early age are usually associated with congenital renal anomaly and about $85 \%$ would lead to renal disease (12). However in older age diagnosis of primary VUR would cause only mild renal damage.

Early intervention either medically or surgically to prevent and slow down the progression of renal impairment is warranted. The administration of prophylactic antibiotics is almost universal in children with VUR. Antibiotic prophylaxis is indicated for the first year for any grade of VUR. It is safe and effective in the prevention of urinary tract infection, however, antibiotic prophylaxis had not been proven to reduce the incidence of pyelonephritis in children with VUR (14).

\section{CONCLUSION}


Early identification of risk factor and predictive factor for severe VUR is the first step before proceeding to appropriate diagnostic and therapeutic approach. Further prospective controlled studies need to be established to get the better outcome in the management of children with VUR. Furthermore regular renal function monitoring is able to evaluate the progress of renal failure. However, larger samples for future studies are necessary.

\section{AUTHORS' NOTE}

RA Aftab and AH Khan have drafted the first version of the manuscript. All authors have been involved in all stages of the study design and have participated in writing the protocol whereas submission to ethical committee was done by NZAN Ismail and RM Ali. MI Ilias and A Nasir were involved in trial statistical analysis and interpretation. MI Ilias critically reviewed the trial and study protocols. All authors approved the final manuscript. Data can be accessed by all the authors throughout and after the study. The authors have no conflict of interest to declare.

\section{REFERENCES}


1. Williams G, Fletcher JT, Alexander SI \& Craig JC. Vesicoureteral reflux. J Am Soc Nephrol 2008, 19: 847-62.

2. Cooper CS. Diagnosis and management of vesicoureteral reflux in children. Nat Rev Urol 2009, 6: 481-9.

3. Fanos V, Cataldi L. Antibiotics or surgery for vesicoureteric reflux in children. Lancet 2004, 364: 1720-2.

4. Yip AYF \& Chan WKY. Outcome of primary vesicoureteric reflux (VUR): A cohort study in Chinese children. HK J Paediatr 200; 12: 260-5.

5. Wald ER. Vesicoureteral reflux: the role of antibiotic prophylaxis. Pediatrics 2006, 117: 919-22.

6. Greenbaum LA \& Mesrobian HGO. Vesicoureteral Reflux. Pediatric clinics of North America 2006, 53: 413-47.

7. Zerati FM., Calado AA, Barroso U and Amaro JL. Spontaneous resolution rates of vesicoureteral reflux in Brazilian children: a 30-year experience. Int Braz J Urol 2007, 33: $204-12$.

8. Caione P, Villa M, Capozza N, De Gennaro M \& Rizzoni G. Predictive risk factors for chronic renal failure in primary high-grade vesico-ureteric reflux. BJU Int 2004, 93: $1309-12$.

9. Silva JM, Diniz JS, Silva AC, Azevedo MV, Pimenta MR and Oliveira EA. Predictive factors of chronic kidney disease in severe vesicoureteral reflux. Pediatr Nephrol 2006, 21: $1285-92$.

10. Zaffanello M, Franchini M., Brugnara M \& Fanos V. Evaluating kidney damage from vesico-ureteral reflux in children. Saudi J Kidney Dis Transpl 2009, 20: 57-68.

11. Woolf AS, Wilcox DT. Understanding primary vesicoureteric reflux and associated nephropathies. Current Paediatrics 2004, 14: 563-7. 
12. Lama G, Russo M, De Rosa E, Mansi L, Piscitelli A, Luongo I and Esposito SM. Primary vesicoureteric reflux and renal damage in the first year of life. Pediatr Nephrol 2000, 15: 205-10.

13. Matsumoto T, Takahashi K, Manabe N, Iwatsubo E \& Kawakami Y. Urinary tract infection in neurogenic bladder. Int J Antimicrobial Agents 2001, 17: 293-7.

14. Montini G, Rigon L, Zucchetta P, Fregonese F, Toffolo A, Gobber D et al. Prophylaxis after first febrile urinary tract infection in children? A multicenter, randomized, controlled, noninferiority trial. Pediatrics 2008, 122: 1064-71.

Table 1: Severity of reflux based on grade 


\begin{tabular}{ll}
\hline Grade & Description \\
\hline Grade I & VUR does not reach the renal pelvis. \\
Grade II & VUR extends up to the renal pelvis without dilation. \\
Grade III & $\begin{array}{l}\text { Mild or moderate dilation of the ureter and the renal pelvis. No or slight } \\
\text { blunting of the fornices. }\end{array}$ \\
Grade IV & $\begin{array}{l}\text { Moderate dilation of the ureter, renal pelvis, and calyces. Complete } \\
\text { obliteration of the sharp angle of the fornices but maintenance of the } \\
\text { papillary impression in most calyces. } \\
\text { Grade V }\end{array}$ \\
& $\begin{array}{l}\text { Gross dilation and tortuosity of the ureter. Gross dilation of the renal } \\
\text { calyces. }\end{array}$ \\
\hline
\end{tabular}

Table 2: Demographic profile of children with VUR in Kelantan

\begin{tabular}{lr}
\hline Characteristics & n (\%) \\
\hline Gender & $15(33.3)$ \\
Female & $30(66.7)$ \\
Male & \\
Race & $40(88.9)$ \\
Malay & $4(8.9)$ \\
Chinese & $1(2.2)$ \\
Indian & \\
Socioeconomic status :monthly income & $21(46.6)$ \\
Less RM1000 & $24(53.3)$ \\
More RM1000 & \\
Education level of parents & $30(66.7)$ \\
Non University & $15(33.3)$ \\
University & \\
\hline
\end{tabular}

Table 3: Clinical profile of children with VUR in Kelantan 


\begin{tabular}{lr}
\hline Characteristics & $\mathbf{n}(\%)$ \\
\hline Laterality & \\
Unilateral & $23(51.1)$ \\
Bilateral & $22(48.9)$ \\
Right & $33(47.8)$ \\
Left & $36(52.1)$ \\
Grade of VUR & \\
VUR I & $5(11.1)$ \\
VUR II & $5(11.1)$ \\
VUR III & $4(8.8)$ \\
VUR IV & $18(40.0)$ \\
VUR V Low grade VUR & $13(28.8)$ \\
High grade VUR & $14(31.1)$ \\
Primary VUR & $31(68.9)$ \\
Secondary VUR & $20(44.4)$ \\
& $25(55.5)$ \\
\hline
\end{tabular}

Table 4: Factors of renal failure (CKD grade 3 - 5) by simple logistic regression model

\begin{tabular}{|c|c|c|c|c|}
\hline Factors & $\bar{n}$ & $\mathbf{B}$ & $\begin{array}{r}\text { Crude OR } \\
(95 \% \text { CI })\end{array}$ & $P$ value \\
\hline $\begin{array}{l}\text { Laterality } \\
\text { Unilateral } \\
\text { Bilateral }\end{array}$ & $\begin{array}{l}23 \\
22\end{array}$ & $\begin{array}{r}0 \\
1.80\end{array}$ & $6.06(1.37,26.76)$ & 0.017 \\
\hline $\begin{array}{l}\text { Gender } \\
\text { Male } \\
\text { Female }\end{array}$ & $\begin{array}{l}30 \\
15\end{array}$ & $\begin{array}{r}0.31 \\
0\end{array}$ & $1.37(0.348,5.42)$ & 0.640 \\
\hline $\begin{array}{l}\text { UTI } \\
\text { Yes } \\
\text { No }\end{array}$ & $\begin{array}{l}28 \\
17\end{array}$ & $\begin{array}{r}0.30 \\
0\end{array}$ & $1.34(0.33,5.49)$ & 0.670 \\
\hline $\begin{array}{l}\text { Income } \\
\text { < RM1000 } \\
>\text { RM1000 }\end{array}$ & $\begin{array}{l}21 \\
24\end{array}$ & $\begin{array}{r}0.61 \\
0\end{array}$ & $1.84(0.51,6.61)$ & 0.346 \\
\hline $\begin{array}{l}\text { Education } \\
\text { Non university } \\
\text { University }\end{array}$ & $\begin{array}{l}30 \\
15\end{array}$ & $\begin{array}{r}-0.15 \\
0\end{array}$ & $0.85(0.22,3.23)$ & 0.640 \\
\hline
\end{tabular}

*Statistical significance $(\mathrm{P}<0.05)$ was observed only in laterality 